\title{
Anarchy, Groups, and Conflict: An Experiment on the Emergence of Protective Associations*
}

\author{
Adam C. Smith ${ }^{\dagger}$ \\ Department of Economics \\ George Mason University \\ 4400 University Drive, MSN 3G4 \\ Fairfax, VA 22030-4444 \\ a411319@gmail.com \\ Phone: 803-493-5631
}

Fax: 703-993-1133

\author{
David B. Skarbek \\ Department of Economics \\ George Mason University \\ 4400 University Drive, MSN 3G4 \\ Fairfax, VA 22030-4444 \\ davidskarbek@gmail.com \\ Phone: 408-691-8448
}

Fax: 703-993-1133

\author{
Bart J. Wilson \\ Economic Science Institute \\ Chapman University \\ One University Drive \\ Orange, CA 92866 \\ bartwilson@gmail.com \\ Phone: 714-628-2830 \\ Fax: 714-628-2881
}

November, 2009

\begin{abstract}
In this paper, we investigate the implications of the philosophical considerations presented in Nozick's Anarchy, State, and Utopia, by examining group formation in a laboratory setting where subjects engage in both cooperative and conflictual interactions. We endow participants with a commodity used to generate earnings, plunder others, or protect against plunder. In our primary treatment, we allow participants to form groups to pool their resources. We conduct a baseline comparison treatment that does not allow group formation. We find that allowing subjects to organize themselves into groups does not lead to more cooperation and may in fact exacerbate tendencies for conflict.
\end{abstract}

Key Words: Nozickian protective associations; Conflict; Anarchy; Experimental economics

JEL Classifications: D60; D70; D83; C92

\footnotetext{
${ }^{*}$ We thank Jeffrey Kirchner for writing the software. The data are available upon request from the authors. We also acknowledge the helpful comments of Michael Maloney, Benjamin Powell, Raymond Sauer, Daniel Sutter, Charles Thomas, Paul Wilson, Bruce Yandle and the Clemson University Workshop in Applied Economics.

${ }^{\dagger}$ Corresponding Author
} 


\section{Introduction}

We often engage in activity that is detrimental to those around us, finding ourselves in situations where the individual incentives facing us lead to suboptimal outcomes at the social level. Indeed many if not most of these activities occur in a setting where no external enforcement is available to settle the conflicts that inevitably emerge. One means of protecting one's self against violent conflict is to ally with other likeminded individuals. By forming alliances for a common defense, groups may hope to encourage recalcitrant individuals to cease activity destructive to the social order. Such tribal behavior is inextricably linked with our development as a species. When viewed through the critical lens of history, Rousseau's "noble savage” is an artificial construct, for man has never existed as an island apart from his peers.

There is much to be said of human achievement through the combined efforts of the group. A quick read through Joel Mokyr's narrative history of human invention and creativity leaves one marveling at the wealth humans have created since classical antiquity (1990). The grandeur of these achievements is blemished, however, by the equally amazing propensity of man to wage wars and commit mass genocide. As Matt Ridley succinctly summarizes, "[w]e may be among the most collaborative social creatures on the planet, but we are also the most belligerent” (1997, p. 193). It is this tension between cooperation and conflict within the context of group formation that we examine more closely in this paper. Using the laboratory method, we conduct a "heuristic experiment" ${ }^{1}$ to examine, as Hirshleifer (2001) puts it, the manner, form, and degree to which "[c]ooperation, with a few obvious exceptions, occurs only in the shadow of conflict” (p. 11).

We draw largely upon the work of Nozick (1974) in developing an interactive framework in which subjects can pool resources as a group for the purposes of both predation and protection of endowments of an income-generating asset. Following Nozick, we call these groups "protective associations." Relative to the canonical laboratory experiment in economics, we impose a minimal structure on our participants to examine a variety of complex strategies that subjects develop to solve the problems they face. Our goal is to observe what institutions, if any,

\footnotetext{
${ }^{1}$ Smith (1982) explains that "[h]euristic or exploratory experiments are used to provide empirical probes of new topics of inquiry....It is through exploratory probes of new phenomena that attention may be redirected, old belief systems may be reexamined, and new scientific questions may be asked" (p. 272-273). This is a fitting description of our motivation for this paper. Using the laboratory method of inquiry, our aim is to shed some light on a question pertinent to political philosophy and constitutional economics.
} 
arise endogenously out of a myriad of possibilities to produce a social order within a group of individuals seeking to attain their own subjective ends.

A critic might ask how we could know whether protective associations historically developed this way. Clearly, we do not know nor claim to be shedding light on this question. We have an example and technique to ask a question about how people build social orders. Wherever, however, or if ever protective associations originated in history, people, from the Aborigines in Australia to the Sámi people of Lapland, had to create a social system to cope with conflict. The structure of this social order necessarily reflected the cultural legacies of the tribe and clearly depended upon the geographic, physical, and economic settings that they faced. Likewise, in our experiment, subjects must create their own social order within the novel context in which we place them. To paraphrase Nozick, we learn much by seeing how social order could have arisen, even if it didn't arise that way. ${ }^{2}$

\section{Protective Associations}

Nozick articulates a theory of how social order could emerge from anarchy through the formation of protective associations. ${ }^{3}$ He suggests "Groups of individuals may form mutualprotection associations: all will answer the call of any member for defense or for the enforcement of his rights...Alliances are designed to allow partners to share risk and resources, gain knowledge, and obtain access to markets” (p. 12). He poses several dilemmas that could mitigate the productive efforts of the association. First, protective associations may need to deal with "cantankerous or paranoid members" along with those who would use the power of the protective association to violate the rights of others. Second, groups will need to resolve internal conflict between its own members to avoid "each calling upon his fellow members to come to his aid”. Third, groups will need to make efficient use of the division of labor and exchange. Finally, groups must decide on what prices or services to provide for those who may desire more extensive or elaborate protection (p. 12-13).

\footnotetext{
${ }^{2}$ See Nozick's similar discussion on the relevance of state-of-nature theory in understanding social processes (p. 79).

${ }^{3}$ Protective associations can be translated into a large domain of groups historically. Families, tribes, clans, cooperatives, corporations and political action committees all take on certain characteristics of protective associations. For the purposes of this study, protective associations are defined as groups that form as a response to a dilemma where incentives lead individuals to act counter to the interests of the community as a whole.
} 
Nozick also recognizes the potential for conflict between groups. He posits three potential resolutions to such conflicts. First, members of a losing protective association may try to join the winning protective association. Second, the protective associations may use geographic location to isolate themselves from other groups. Third, rival protective associations may find themselves equally matched and will come to a tacit agreement not to fight or to resolve conflicts in a more peaceful manner. Nozick argues that eventually, however, the largest protective association in a local area will subsume all other protective associations through force or contract. This “invisible-hand process,” by which spontaneous forces create one overarching group, emerges because the most efficient group is able to attract new members due to its superior benefits, and it will "buy-in" outside members into its ranks in order to militate against further predation against its current members. ${ }^{4}$

Economists have utilized the notion of protective associations as a thought experiment to compare the merits of private and public law enforcement. ${ }^{5}$ As this literature is mostly peripheral to the purposes of this paper, we mention only a few related points. ${ }^{6}$ Friedman (1989) argues that protective associations would bring about a more efficient enforcement of law, and would prevent conflicts with each other through contract. Protective associations have a monetary interest in stability and therefore the protracted costs of conflict outweigh the benefits of contracting with other associations to avoid this conflict. Friedman, therefore, suggests that a stable equilibrium should emerge in the long run as the opportunity cost of conflict is too great.

Cowen (1992) argues that the assertion of a stable equilibrium involving a multitude of protective associations ignores the underlying factors that will instead lead these associations inexorably to monopoly. He maintains that protective associations would benefit from network externalities, which would cause a collapse from a multitude of protective associations into

\footnotetext{
${ }^{4}$ A previous commentator of this paper remarked on the similarity between this argument and the Coasian depiction of the organizational genesis of the firm. Just as firms "buy-in" labor and capital inputs rather than go through market arrangements, so does the protective association internalize conflicting parties rather than allow such conflict to play out among decentralized forces.

${ }^{5}$ In a highly original piece, Becker \& Stigler (1974) argue that bringing more law enforcement into the realm of the market instead of the public domain would provide enforcers with better incentives to accommodate their respective clients. While this argument has been criticized (see Landes \& Posner 1979; Cowen 1992; and Sutter 1995), several arguments have been made in defense of protective associations as a viable alternative to the public provision of law enforcement (Friedman 1989, 1994; Caplan \& Stringham 2001).

${ }^{6}$ Research on protective associations relates more broadly to the literature examining how and to what extent selfenforcing exchange can achieve social cooperation. This includes research on private law enforcement (Friedman 1989; Benson 1990; Stringham 2007), community and commercial dispute resolution (Ellickson 2005), international trade (Grief 1993; Leeson 2007a, 2007b, 2008), and property rights in the historical context of the American western frontier (Anderson and Hill 2004).
} 
several or even one. After this collapse, the inefficiencies associated with the group's monopolistic hold on protection will arise. In response, Caplan \& Stringham (2001) maintain that associations would have difficulty overcoming the obstacle of collusion that all oligopolies face. They argue that the incentive to renege and offer services that are more competitive will overcome the incentive to collude.

Finally, several papers are worth noting from the economic analysis of conflict literature. These papers emphasize the stability of various forms of "anarchy” given certain conditions (e.g. Skaperdas 1992; Hirshleifer 1995; and see Durham et. al. 1998, Carter and Anderton 1999, Duffy and Kim 2005, and Lacomba et. al. working paper for experimental applications of this research). Drawing on these initial models, a few efforts have incorporated coalition formation into the analysis. Skaperdas (1998) examines the formation of alliances within conflict. He finds that coalitions will emerge if there are increasing returns to pooling resources used for appropriation. Noh (2002) introduces the problem of distribution and collective action within the alliance. He still finds that alliances are feasible given certain assumptions regarding these intragroup costs and the returns to pooling resources. Esteban and Sakovics (2003) find, however, that the conditions necessary for a "grand coalition" to emerge are more stringent than the

previous literature indicates. Within the parameters of their model, they find that the costs of intra-group conflict will outweigh the benefits of inter-group cooperation.

\section{Experimental Design and Procedures}

\section{A. Environment and Institutional Parameters}

We draw upon the design and procedures in Powell \& Wilson (2008) in building our own experimental design. We endow six subjects with a number of units of a commodity $x$ that earns $\$ 0.00077$ every second that it is designated as an earnings unit $e$. Prior to receiving this endowment, each subject takes a short quiz that includes questions drawn from SAT exams. We utilize the quiz to induce subjects with a sense of entitlement towards their endowments. Previous experimental work indicates that this procedure does indeed generate a sense of an earned property right (see e.g. Hoffman and Spitzer, 1982, 1985; Hoffman et al., 1994; and Cherry et al., 2002). The endowments of $x$ are: 19, 21, 23, 25, 27, and 29 with the subject scoring highest on a quiz receiving the endowment of 29 , second highest 27 , and so forth. Ties are determined by giving the higher allocation of units to the person who finished the quiz first. 
Subjects can convert these initial endowments of $x$ into units of either offense $o$, defense $d$, or hold as $e$ once the experiment begins. Recall that holding one unit in $e$ generates $\$ 0.00077$ per second. If, for example, a subject with the average endowment of units (24 units) were to hold her earnings in $e$ for the entire session (assuming no units are taken), then she would earn a payout of $\$ 44.35 .^{7}$

Subjects may use offensive units to take units of $x$ from another subject, and use defensive units to protect the subject's existing units of $x$. Units placed in defense and offense do not earn money and cannot be taken. Conceptually this is reasonable as tools used for predation and protection (firearms, security systems, walls, etc.) are not easily stolen and do not usually generate income for their owners. ${ }^{8}$ The opportunity cost is the productive value of holding units as $e$. To incorporate a transaction cost, converting units of $e$ into either $o$ or $d$ takes 10 seconds. During the conversion time the unit does not earn money, and as many units as are available can be moved at one time.

Subjects can use the units of offense to take $e$ from another subject. The probability that an attempt to plunder is successful is determined by the number of offensive units (oa) attacker $a$ has compared to the number of defensive units $\left(d_{t}\right)$ the target $t$ under attack has. Specifically, the success rate for the attacker is $\frac{o_{a}}{o_{a}+d_{t}}$. After any attempt to take earnings units from other subjects, offensive units are not available for use for 20 seconds. This additional transaction cost simulates the recovery costs of using force.

Individual subject holdings of $e, o$, and $d$ are publicly observable to all participants throughout the experiment. We notify subjects of all attempts at taking and the result of the attempts. Individual subject identities remain anonymous at all times.

In what we will call the Nozick treatment, subjects are also able to form subgroups with other subjects. A subject starts a group by selecting a button "Start Group" and then sending invitations to other subjects to join. These invitations come in the form of a prompt on the invited subject's screen. The invited subject can either accept or reject the invitation. A subject cannot join — or even be invited — if she or he is currently a member of another group. Only the founding member of the group can extend invitations. Finally, no member can be removed from

\footnotetext{
${ }^{7}$ This is calculated as follows: Maximum Median Earnings $=24$ units $\times 40$ minutes $\times 60$ seconds $\times 0.00077 \$ / \mathrm{sec}=$ $\$ 44.35$.

${ }^{8}$ Such investments may be categorized as the rent-seeking costs of theft (see Tullock 1967).
} 
a group once she or he joins, though any subset of the group can always leave to form another group.

Groups have the added ability to pool their respective defensive and offensive capabilities. Let $G=\{1,2, \ldots, 6\}$ denote the set of all individuals and $G_{i}$ denote the ith (nonempty) subset of persons formed by a partition of $G$. Once a group is formed, members of the group automatically share all units of defense, i.e., the number of defensive units for each person in $G_{i}$ is $\sum_{j \in G_{i}} d_{j}$. For example, if a person with $o_{a}$ units of offense attacks a target $t$ currently part of a group, the probability of success for the attack against $t$ is $\frac{o_{a}}{o_{a}+\sum_{j \in G_{i}} d_{j}}$ as opposed to merely $\frac{o_{a}}{o_{a}+d_{t}}$.

In contrast to the defensive units, which we automatically pool, group members also have the option of pooling offensive units on a voluntary basis. To pool units of offense, subjects click on a button above the group member they wish to lend their offensive units. The lender must send all or none of their units of offense to the designated group member. While the lender loans these units out, she or he has no ability to take units from any other subject. The reason is that the person who the lender offers the units to is effectively using the units for that lender. At any moment, the lender can instantly regain control of their units of offense by clicking the button above the designated group member a second time. Let $G_{i}^{o}$ denote the subset subjects that have lent a subject their $o$. Subjects who borrow $o$ are able to use these units as if they were their own, meaning the probability of success for attack against target $t$ now becomes $\frac{\sum_{j \in G_{i}^{o}} o_{a}}{\sum_{j \in G_{i}^{o}} o_{a}+d_{t}}$. In addition to this change in probability, subjects who borrow $o$ are also able to take more than one $e$ in any given attempt. The reason for this is that they are effectively using the units of the lender in the attack. Therefore, any successful attack counts as a successful attack for each participating member and takes one unit for every member that contributes to the pool of offensive units, conditional that the target has that many units to take. Otherwise, the successful attack will remove all the units of the target. For instance, if the three subjects lend a person 
their units, then this person will now take four units rather than one any time she or he is successful.

If a subject attempts to plunder another subject within their own group, however, then neither subject commands the pooled resources $d$ or $o$ of the group. It is as if they are attacking outside the apparatus of the group. ${ }^{9}$

We also allow subjects to send $e$ to other subjects. They may perform this by entering the desired amount of $e$ and the intended subject of these units into a text box and then clicking send. If subjects voluntarily send units using this mechanism, then they permanently reside with the recipient (at least until the recipient is plundered or voluntarily sends units out themselves).

Subjects are able to communicate using both a public and a private chat room. All subjects in the experiment can read messages sent to the public chat room, which is visible to all subjects throughout the experiment. Groups have the additional ability to communicate through a private chat room that is only visible to subjects within the particular group. We allow this private communication to allow groups to more easily facilitate cooperation within a mostly conflictual environment. Previous experimental research shows that communication can indeed increase the likelihood of cooperation (see Ostrom et. al. 1992). The subject is able to observe successful and unsuccessful takes by her and others. We display the amount of time passed in the session, earnings per second, and total earnings and update every second. In addition, the subject can see how many defensive units and offensive units that her group controls at all times. Figure 1 displays a sample screen shot for this treatment.

\section{B. Baseline Treatment}

As a baseline to the Nozick treatment, we also conducted a treatment that did not allow subjects to form groups, which we label the Hobbes treatment. Subjects in this treatment are not able to form groups and thus do not have any of the additional abilities that go along with group formation, including the ability to lend offensive units, pool defensive units, or communicate through a private chat room.

\footnotetext{
${ }^{9}$ See Noh's discussion of the need to reduce intra-agency private enforcement of rights (p. 15).
} 


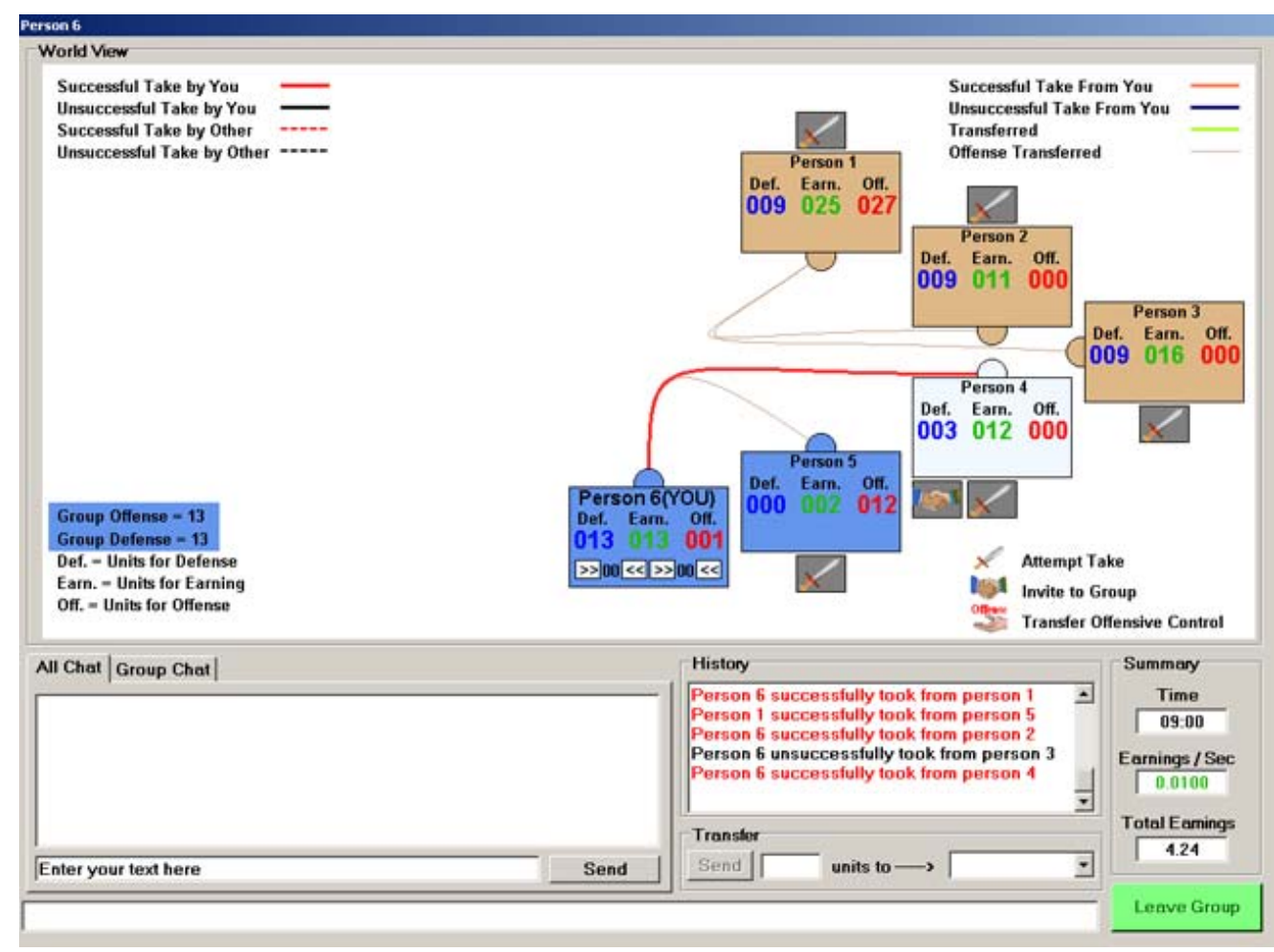

Figure 1. Screenshot for Nozick Treatment

\section{Procedures}

We conducted six sessions in each of the two treatments, for which we recruited 72 subjects from the at-large undergraduate population at George Mason University. We seated subjects at a visually isolated computer terminal where they interacted anonymously with other participants. Sessions lasted 40 minutes after approximately 15 minutes of instructions. We recruited subjects for an experiment that could last up to 90 minutes, but we left the actual experimental interaction time undisclosed to mitigate end-game effects of a necessarily finite experiment. Subjects received instructions about how to participate in the experiment (see Appendix 1) followed by a quiz of 10 questions. Each session had six participants who only participated in a single session of this experiment. Subjects received $\$ 7$ for showing up on time in addition to what they earned in the experiment. The average earnings without the show-up payment were $\$ 14.50$. We paid out earnings privately at the conclusion of the experiment.

\section{Hypotheses on Anarchy}

In designing our experiment to examine the circumstances envisioned by Nozick, we utilize, relative to a canonical economic experiment, a rather open-ended framework to grant our 
subjects the flexibility to create their own social order based upon their repeated interactions with one another. We knowingly trade off the pinpoint predictions of a static Nash equilibrium for the even tougher challenge of forming a stable social order in a continuous time anarchical environment bereft of external enforcement. Nevertheless, the replicable conditions of our precisely specified environment generate several hypotheses inspired by Nozick's thesis. First, we hypothesize that the Nozick treatment will be more efficient on average than the Hobbes treatment. We determine efficiency by the ratio of units placed into $e$ relative to the total number of units available. Following the terminology in Skaperdas (1992), we define "full cooperation" as occurring when all available units in the economy are placed in $e$. More formally, efficiency at time $\tau$ is defined as $E_{\tau}=\frac{\sum_{k=1}^{6} e_{k \tau}}{\sum_{k=1}^{6} x_{k}}$, where $\sum_{k=1}^{6} x_{k}$ is always $144 .{ }^{10}$ The "average efficiency" in a session (of 2400 periods) is $\frac{\sum_{\tau=1}^{2400} E_{\tau}}{2400}$. Nozick's claim that protective associations lead to a social order serves as the foundation for this hypothesis.

Naturally, every experimental "test" of a theory is a joint test of the theory and the applied context in which the theory is implemented (Smith 2002, 2008). If we observe that our economies in this first laboratory experiment regularly deviate from Nozick's philosophical argument, then only with more observations under a wide variety of environmental and institutional conditions will it become possible to deduce with more confidence whether these systematic deviations are due to an auxiliary hypothesis on how an experiment is implemented, or due to the circumstance that the foundations of Nozick's argument do not comport with the facts of human sociality. In either case, we have generated a set of facts against which to examine further conjectures.

Second, we hypothesize that a single group will emerge in the Nozick treatment that will eventually include all active members. According to Nozick, a monopoly on force can emerge in the market for protection without the help of artificial entry barriers, as this market is both relative and violent. In other words, the value of a protective association is determined according to its relative abilities compared with competing associations. Furthermore, this

\footnotetext{
${ }^{10}$ A total of 1 unit in each of two Nozick sessions was lost in the ether when a subject transferred multiple units. As $0.7 \%$ of the total number of units, we do not consider this to be a consequential software glitch.
} 
competition is violent, so joining the association with an absolute advantage in violence is pertinent for the rational consumer. Simply stated, “customers will not stably settle for the lesser good and competing companies are caught in a declining spiral” (p. 17). Nozick conjectures that as one group becomes relatively more powerful than its rivals, its members will either terminate the remaining individuals ${ }^{11}$ or find it beneficial to provide protective services to the unaffiliated members to reduce the risk of conflict.

Third, we hypothesize that the ability to communicate in real time allows subjects to coordinate better on cooperative strategies and settle their conflicts, resulting in higher efficiency in our Hobbes treatment relative to the observations in Powell \& Wilson. As mentioned above, Ostrom \& Walker (1992) find that allowing subjects to communicate can lead to a pronounced change in rates of cooperation. The other difference between our Hobbes treatment and Powell \& Wilson is that we allow subjects to transfer units voluntarily. We incorporated this feature into our baseline treatment primarily to further limit the differences between treatments in our comparative analysis. We also added this feature in recognition of Buchanan's argument that "[t]o secure an initial agreement on positive claims to goods or to resource endowments, some transfer of goods or endowments may be required. That is to say, some 'redistribution' of goods or endowments may have to take place before a sufficiently acceptable base for property claims can be established” (Buchanan 1975, p. 83). Though it would seem that the addition of these two features reduces the comparability to Powell \& Wilson, we do find the results of our Hobbes treatment closely approximate theirs with a few exceptions noted below.

\section{Results: Anarchy, State, or Utopia?}

In reporting our results, we first formally test our hypotheses regarding Nozick and Hobbes treatments. To convey a deeper level of the rich interactions in these societies, we next summarize our twelve Nozick and Hobbes sessions using evidence from chat transcripts, along with general observations about each session. Each session description also includes a chart that displays the allocation of units between the three uses at each second of the session. The charts for the Nozick sessions contain a line plot of the Herfindahl-Hirschman Index of concentration

\footnotetext{
${ }^{11}$ Following Powell \& Wilson (2008), we define "termination" as occurring when a subject has 3 or less units of $x$.
} 
for each moment of the session. ${ }^{12}$ This quantifies the extent to which a single protective association emerges in the session. Finally, we offer qualitative remarks to organize the general patterns that we observe.

\section{A. Testing Our Hypotheses}

\section{Efficiency}

In assessing our hypotheses, we find several surprising results. In terms of efficiency, the Nozick sessions displayed uniformly low levels of cooperation with only one session (N6) achieving efficiency greater than 50\%. The Hobbes sessions on the other hand were either highly efficient $(H 1, H 2)$ or dismally inefficient $(H 3, H 4, H 5$, and $H 6)$. Table 1 reports the efficiency levels of the six Nozick sessions along with the Hobbes sessions. ${ }^{13}$ Using a nonparametric Wilcoxon rank sum test, we fail to reject the null hypothesis that the average efficiency of the Nozick and Hobbes sessions are equally efficient $\left(W_{6,6}=20, p\right.$-value $=0.5909$, one-sided test).

\begin{tabular}{|r|r|r|}
\hline \multicolumn{3}{|c|}{ Table 1. Average Efficiency } \\
\hline Session & \multicolumn{1}{|c|}{ Nozick } & Hobbes \\
\hline 1 & $22.7 \%$ & $60.6 \%$ \\
\hline 2 & $34.4 \%$ & $88.2 \%$ \\
\hline 3 & $17.6 \%$ & $11.6 \%$ \\
\hline 4 & $26.7 \%$ & $14.7 \%$ \\
\hline 5 & $13.3 \%$ & $13.7 \%$ \\
\hline 6 & $51.4 \%$ & $21.8 \%$ \\
\hline Average & $27.7 \%$ & $35.1 \%$ \\
\hline
\end{tabular}

The two Nozick sessions in which full cooperation arose (N2 and N6) led to moderate levels of efficiency but the remaining four were low. Subjects in both sessions $H 1$ and $H 2$ were able to attain full cooperation very early in their respective sessions. Because the life of a laboratory economy is necessarily finite, unlike the naturally occurring world in which time marches on, a frequently raised question is whether the subjects just need more time to "learn," so they can conform to the outcome predicted by our hypothesis concerning the higher

\footnotetext{
${ }^{12}$ We calculate the HHI as the sum of squares of the percentage share of units under the control of each group at any moment of time. Subjects who were not part of a group were counted as a group of one. Thus, the HHI at the start of each session contains six shares.

${ }^{13}$ The relative comparison between Nozick and Hobbes does not change significantly when average efficiency of the sessions is broken down into halves or thirds.
} 
efficiencies of the Nozickian societies. If this is so, then why did sessions N2 and N6 not need more time to reach $100 \%$ efficiency? And why did sessions $H 1$ and $H 2$ need such little time? Apparently, our experiment is sufficiently long enough to generate a variety of outcomes, which is exactly what we need to help us to understand what factors account for better or worse performance in these economies.

\section{Group Formation}

In terms of group formation, the Nozick sessions were marked both by cooperative and conflictual tendencies. Contra the invisible hand process proposed by Nozick, we do not observe an inevitable tendency for the subjects to form a single group. This was most strikingly evident in session N3. Not only did the single group break back down into several subgroups, but also there was no change in the amount of plundering before or after the overarching group formed. Moreover, Sessions N2 and N4 developed a relatively stable equilibrium of two distinct groups for most of their respective sessions.

\section{Our Hobbes Treatment vs. Powell \& Wilson}

Contrary to our hypothesis, we find no evidence that the ability to communicate in real time allows our subjects to coordinate better and settle their conflicts relative to the similar, but communication-free exercise in Powell \& Wilson (2008). Comparing our 6 sessions with their 8 sessions, one of our sessions is the most efficient at $88.2 \%$, and another is the most inefficient at $11.6 \%$. Not surprisingly then, we fail to reject using a Wilcoxon test the null hypothesis that the average efficiency of the two experiments are equally efficient $\left(W_{8,6}=31.5\right.$, $p$-value $=0.8375$, one-sided test). Succinctly summarized, communication is not a sufficient solution to this particular problem.

\section{B. Summary of Nozick Sessions}

\section{Session N1}

Very few groups formed in N1. There were numerous attempts to start groups by a few of the subjects but almost all of these invitations were rejected. The group formation that occurred was sporadic and short-lived, and no group formed until after the experiment was past the two-thirds mark. 
The average efficiency was also very low in this session (22.7\%) due to constant plundering, and two subjects were terminated. An interesting development occurred towards the end of the session with at least three of the active subjects proposing a truce. One subject said, "hey guys listen i got a way to increase our earnings. lets all place our units in earn and let it increase per sec. no one attack each other.” Two of the other subjects seemed receptive to this, but the session ended shortly after these comments. It was not apparent at that time that they had reached an agreement.

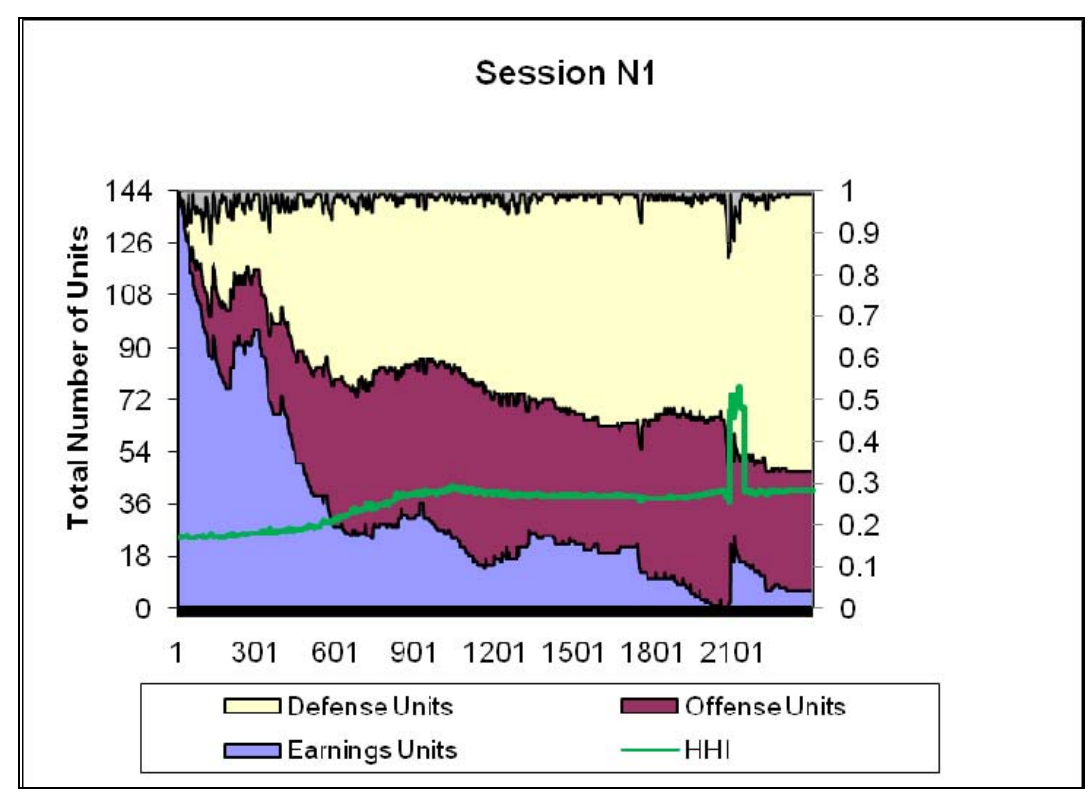

Session N2

Two groups emerged almost immediately in this session. Both groups pooled their offensive capabilities, and in each group, one of the subjects took the lead in offering advice on how to utilize this feature of the experimental interface. About one-third of the way into the session, two groups had emerged with three members each.

One group focused, though not exclusively, on increasing their units of defense and held the rest of their assets in earnings, while the other group put nearly all of their units into either offense or defense at any one time. Eventually, one subject had the idea of a truce by stating in the group's private chat room, "everyone SHOULD just stop attacking and earn.” This led the group to further decrease their offensive units but resulted in no parallel behavior by the other group. Later the same subject wrote a message in the public chat room that said, "there needs to 
be an agreement between everyone. see no one is making money right now." A subject from the other group then responded in the public chat room, "should we all agree not to attack."

The two subjects who had communicated a truce in the public chat room then went back into their respective group chat rooms and prompted their group members to put all units into earnings. One of the subjects asked for a signal of trust from the other group by asking them to "take your units out of offense so i can trust you." There was still some hesitation as each subject began to pool more and more units into earnings. One of the groups even suggested a trigger strategy in case the other group defected. However, all subjects eventually put all units in earnings and abided by the agreement.

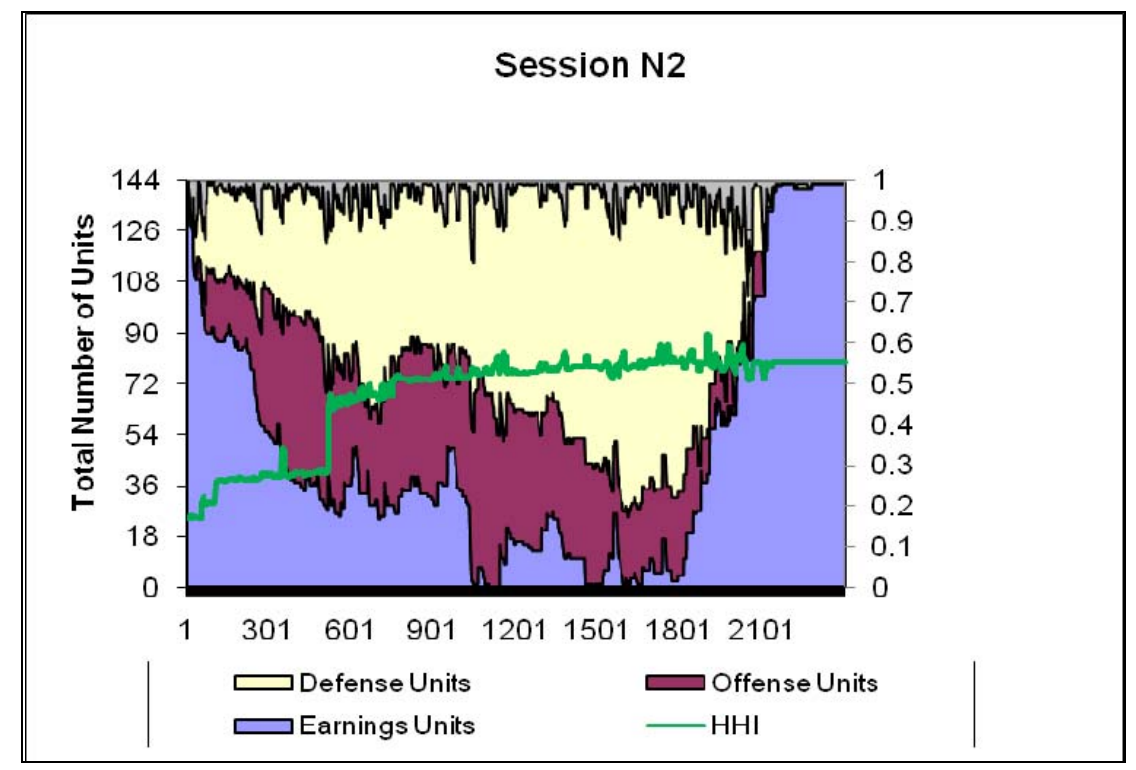

\section{Session N3}

Group membership in this session was erratic with members accepting invitations but then leaving the group soon after. As a result, groups were not very stable. It appeared that subjects did not develop a sufficient level of trust within groups as there was very little offensive pooling. At the same time, the number of attacks was quite large, and the average efficiency suffered as a result (17.6\%). There was no indication of any interest of a truce. No clear leaders emerged among the subjects to instigate such an outcome or even to coordinate attacks. One person was terminated.

It is interesting that the majority of the chatting took place in the public chat room versus private group chat rooms. An especially interesting development occurred when all six subjects 
were part of the same group just over halfway through the session. Yet this led to no observable decrease in plundering! The group eventually dissolved. There was no attempt at cooperation at this time or any other in this session.

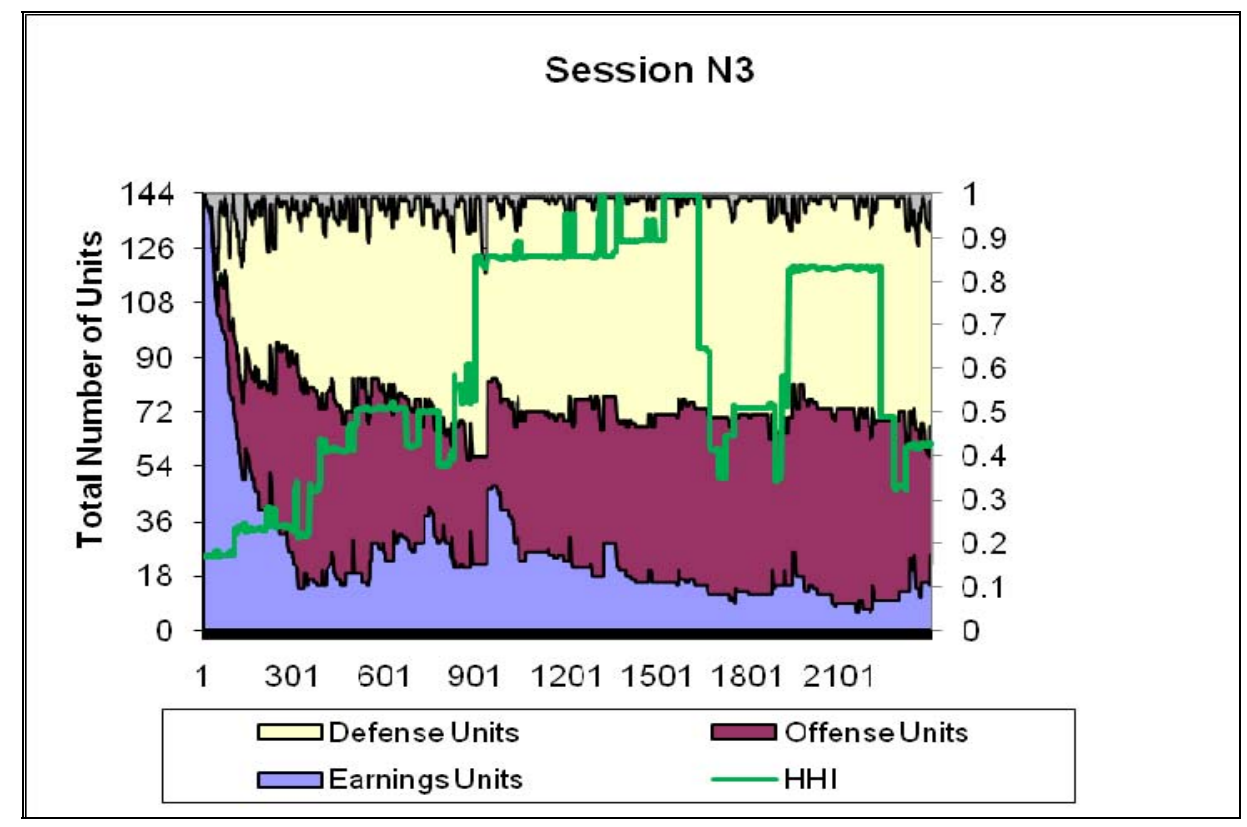

\section{Session N4}

Two groups formed about a third of the way through this session. These two groups contained two members each until about halfway through the session. At this time, both groups invited one of the remaining two members. The two groups did not coordinate their attacks in any systematic way. Pooling occurred occasionally but was sporadic, as the groups never came to an agreement on who would attack and how they would distribute the plundered units. Attacking was mostly uniform across the session though efficiency did improve towards the end of the experiment.

Efficiency was relatively low in this session (26.7\%), and one person was terminated. By the end of the session, four of the five active subjects were in one group, which may have been why efficiency started to rise towards the end of the session. There were no explicit attempts to cooperate, however. 


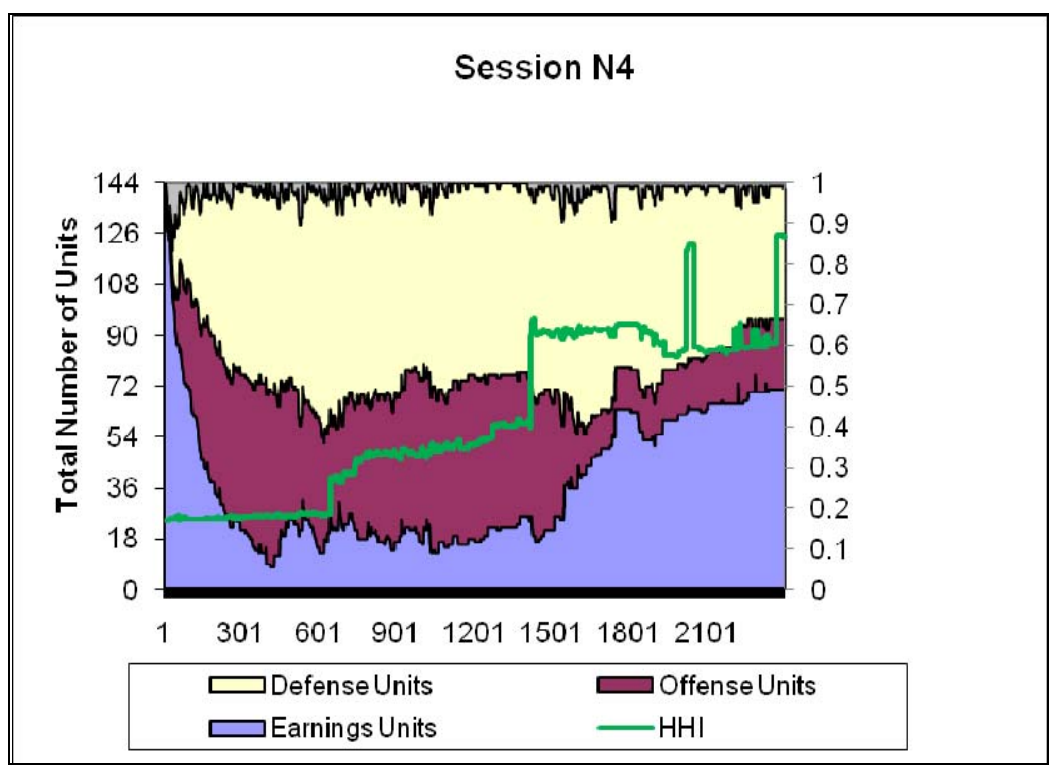

\section{Session N5}

This session had a similar pattern of group development to Session N4. For about half of the session there were two groups with two members each. There were no explicit attempts to pool offensive resources within the groups. Eventually, one of the groups acquired another member and finally a fifth member. The remaining sixth subject never joined the group. By the end of the session, this remaining subject was attempting to plunder but was unable to get through the defenses of the five combined subjects. The large group pooled more of their units into earnings as the session reached its conclusion. However, overall efficiency was quite low (13.3\%) due to the earlier plundering. Like the two previous sessions, there was no attempt to communicate a truce among the subjects.

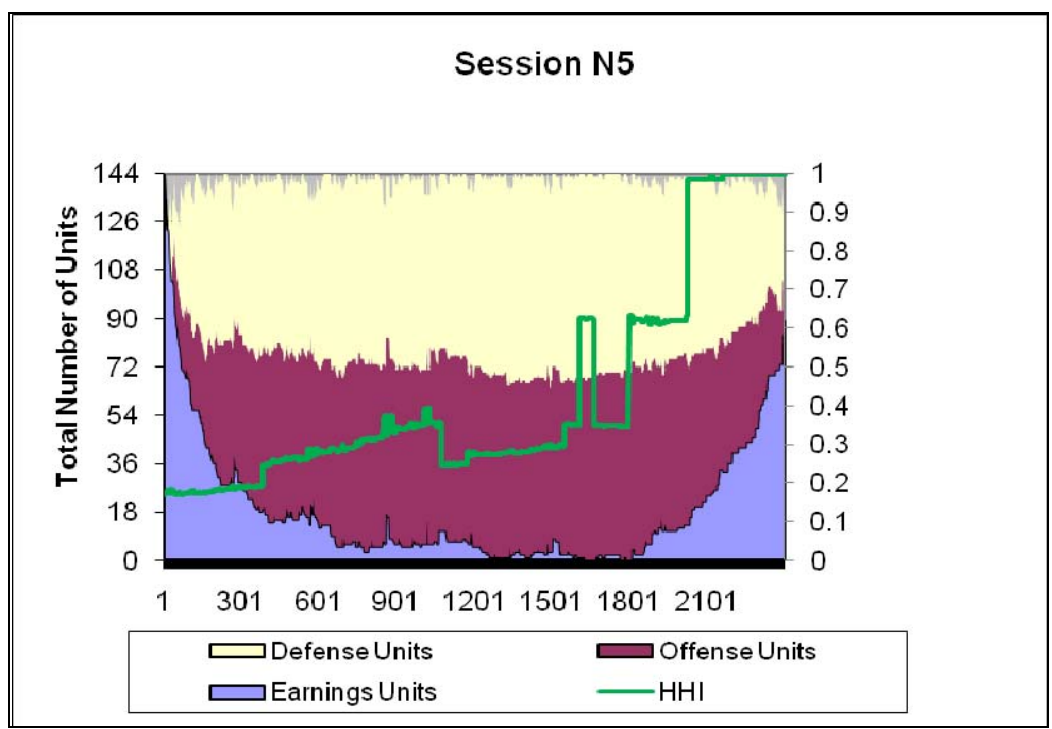




\section{Session N6}

This session started like much of the others with two groups forming. One of the groups was especially well coordinated and quickly pooled their offensive capabilities. This led to a significant amount of plundering from the other group. Halfway through the session, a "leader" in this group proposed a truce by inviting the others to join their group. This led two of the remaining three members to join what one subject termed their "alliance." Eventually, the remaining subject joined as well.

From the halfway mark on, efficiency steadily climbed. By the end of the session, all available units were in earnings. Note that this session and Session N2 are the only Nozick sessions where full cooperation emerged.

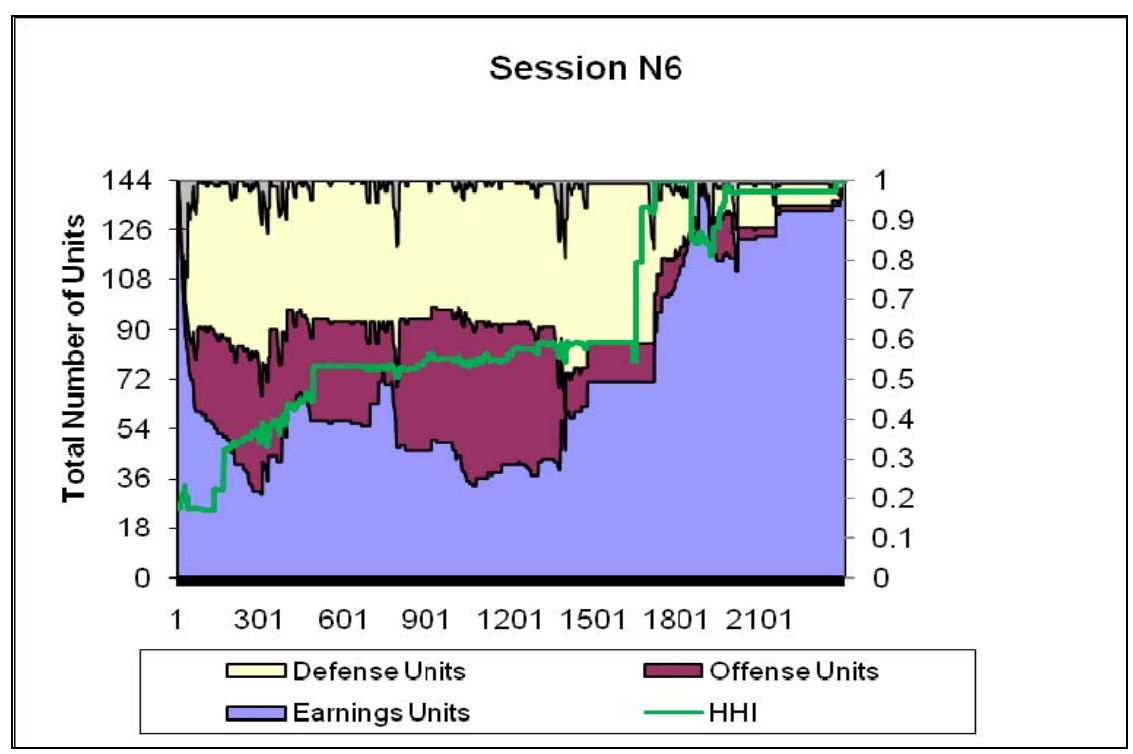

\section{Summary of Hobbes Sessions}

\section{Session $\mathrm{H} 1$}

The first posted message in this session was "no one is earning money." Shortly thereafter, another subject proposed an agreement to stop predation by offering, "how about we all put ours in earn and not take from each other so at least we earn something," which the subjects discussed and agreed to. At one point during this discussion, a subject tried unsuccessfully to take from another subject, but this was the last attempt at predation in the session. The subjects agreed not to take from each other with one subject offering, "and if 
someone gets greedy everyone else will just steal from them.” The subjects reached full cooperation shortly after the halfway mark in this session.

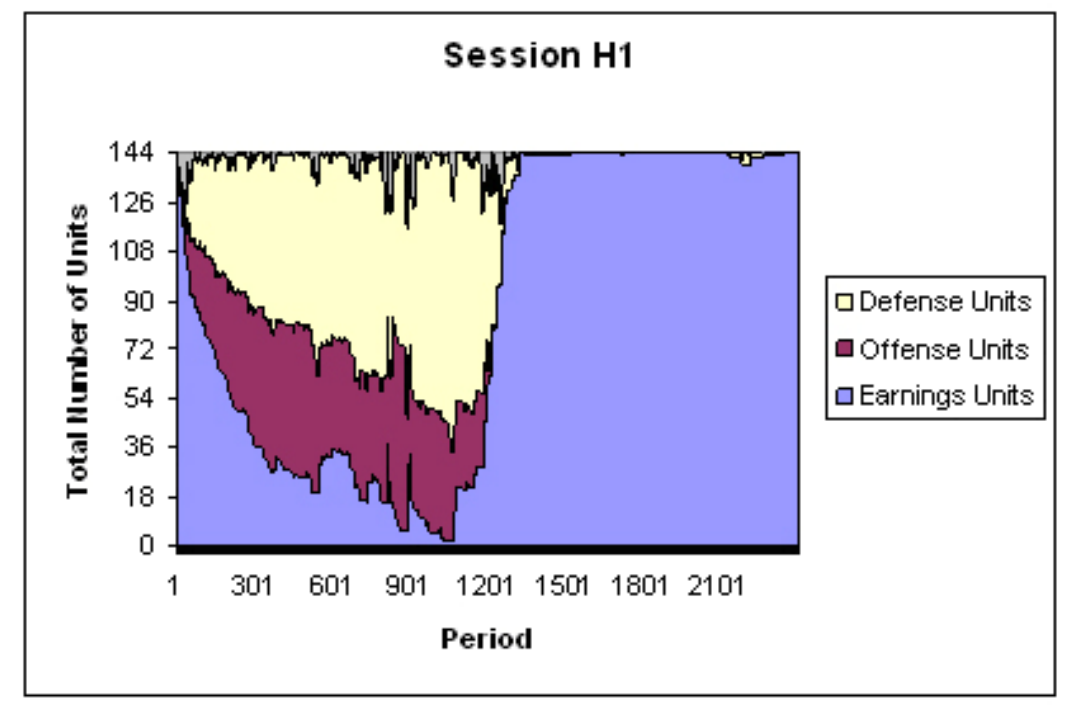

\section{Session H2}

Predation was largely absent in this session relative to the others. In fact, only 23 attempts to plunder occurred in this session. This is due perhaps to one subject's proposal for an agreement to stop conflict very early in this session. The same subject also proposed the strategy of taking units away from anyone who continued to hold units in offense. The proposal did not work, however, and the subjects continued to attack each other. Several began to recognize, however, that they could do better if they all refrained. For example, one subject said, "we can allmake a lotmore if you stop [attacking].”

After testing several parameters of the experimental environment, several subjects attempted to persuade others to invest fully in earnings. One subject was concerned that the subject who organized the agreement was making more than everyone else, saying, "this was your idea i want to know how much you are making" because "it wouldnt be fair if you have more then everybody." The "leader" of the effort to cooperate replied, "i'm making .0216." At this point a third subject came to the defense of the leader by saying that "if he is [making more money] its becuase he got more questions right," in reference to the way initial earnings were allocated. They continued to discuss the fairness of the distribution of earnings and whether subjects should return units they had previously taken . 
Full efficiency was reached less than a third of the way through the session. This efficiency was interrupted only once during the remainder of the session when one subject broke the agreement by successfully taking from another subject. The plundered subject immediately responded by taking a unit back. There were no more takings for the remainder of the session.

The subjects in this session were very concerned about distributive issues. There were several proposals for ways to improve the distribution, but some noted the difficulty in determining who owed compensation to whom, because everyone had stolen from everyone. One subject suggested that everyone should have an equal amount. Another subject told everyone to "give back whatever you stole." The subjects agreed to this last strategy and began transferring units to compensate for previous takings for the remainder of the session.

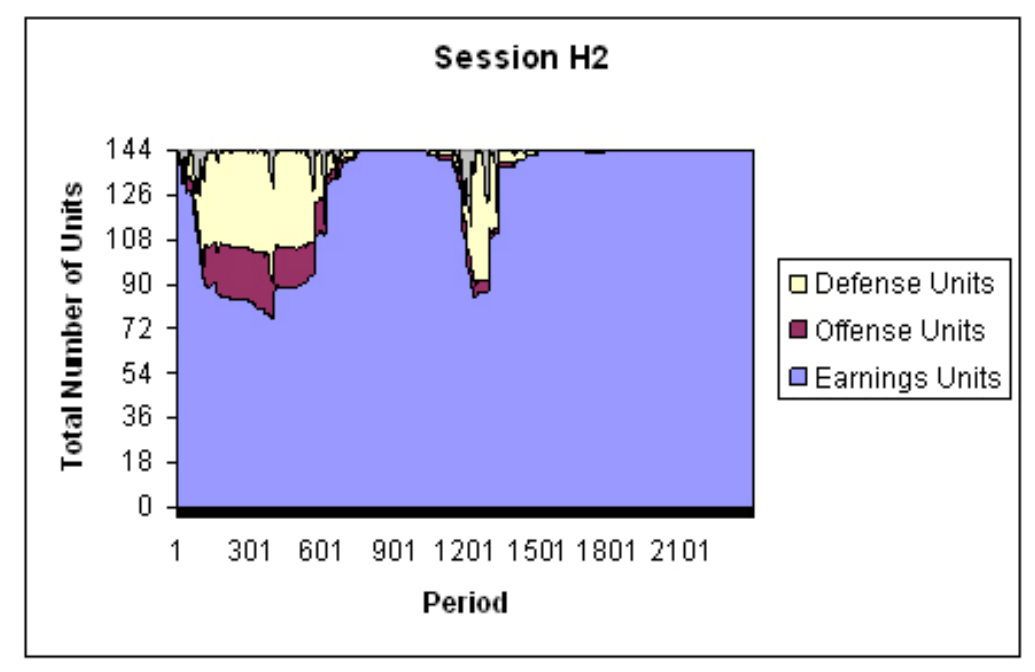

\section{Session H3}

The most notable feature of this session was the lack of chat. The first message did not appear until the second half of the session, when one subject asked, "Subject 2 can you send some units to 6.” Following this request, subjects posted several similar messages prompting subjects to redistribute units voluntarily. For example, one subject told another to "give some to Subject 4 dont be greed...he or she needs it.” Towards the end of the session, a subject proposed that they all "put everythng in earnings." Nevertheless, plunder continued until the end of the session. Efficiency was persistently low and never went past the 50\% mark once the session began. 


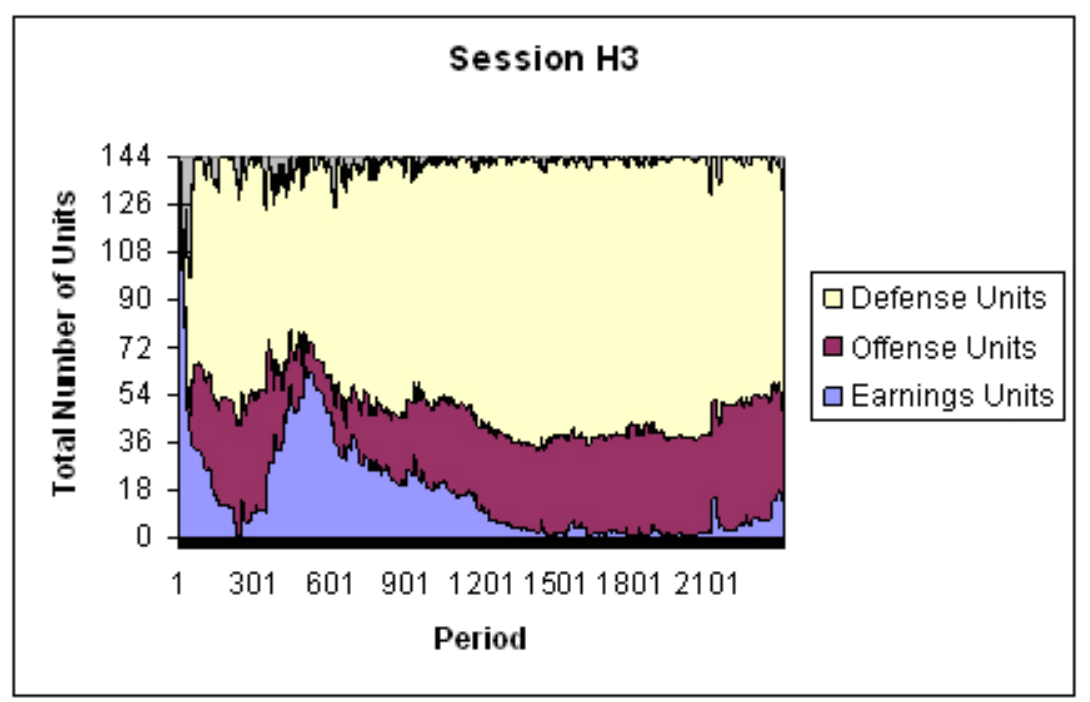

\section{Session $\mathrm{H} 4$}

After several minutes, the participants began chatting, and one subject was terminated early. One subject proposed, "want to make a pact whereever ones puts there stuff in earnings and doesnt take from anyone and just collect mmoney?” There was some discussion about a possible agreement, and several subjects said they would comply. However, one subject held out and did not respond even when directly addressed by the other subjects. The subject rarely engaged in conversation. When he did, it was unclear what he meant. For example, he interjected "game over" in the midst of a discussion regarding cooperating. Perhaps the holdout thought that if all subjects begin to cooperate, the experimenter would end the session arbitrarily or perhaps that refraining from dialogue would increase his bargaining power (See, for instance, Schelling 1960).

After the halfway mark, the subjects discussed making an agreement without the holdout. They come close to agreeing on a contract, but it is unclear if they ever really made one. For instance, one subject complained that they could not make money if the holdout continued to take from them. In the remainder of the experiment, the subjects pleaded with the holdout, who remained silent. This session was particularly interesting because all subjects clearly desired agreement except for one, yet this one subject's refusal to commit to an agreement was an effective obstacle to implementing it. 


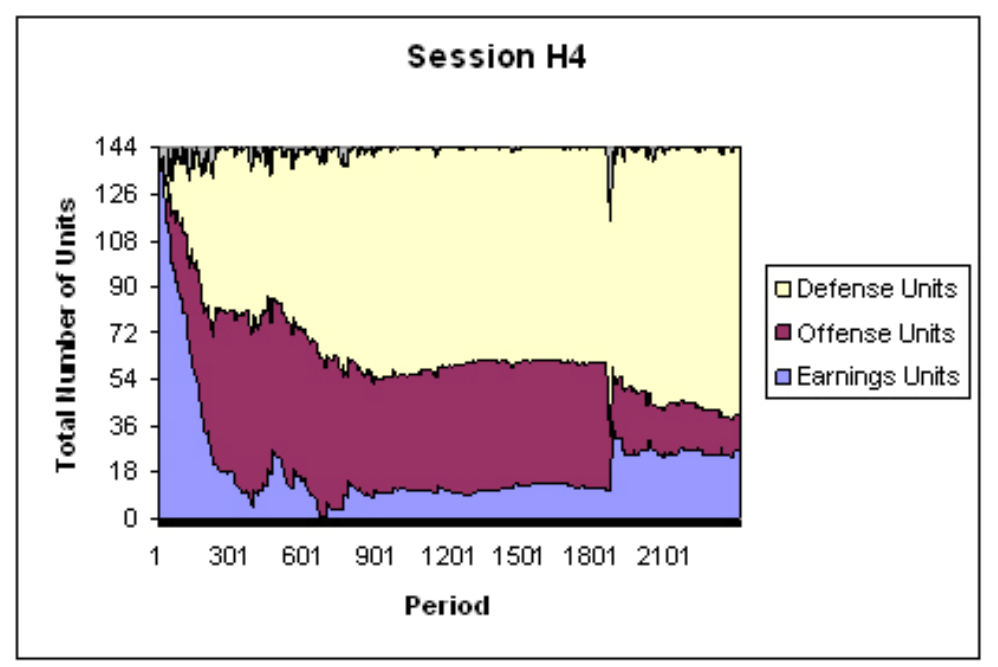

\section{Session H5}

Communication began early in this session, as a subject proposed cooperation by asking, "What would happen if we all just put everything in earnings.” Later another subject explicitly proposed a cooperative agreement by asking, "does everyone want to try setting a defense for all of us and depositing all our offense in earning and not attacking." The others did not agree and continued to take from each other. The initial instigator for cooperation raised the idea again saying, "I vote we put it $100 \%$ in earnings" and "Can we agree on dumping all our points into earnings?” Four of the subjects agreed but attempts at plundering continued throughout the session. One of the two subjects who did not agree to the cooperative agreement did not send any messages during the entire session.

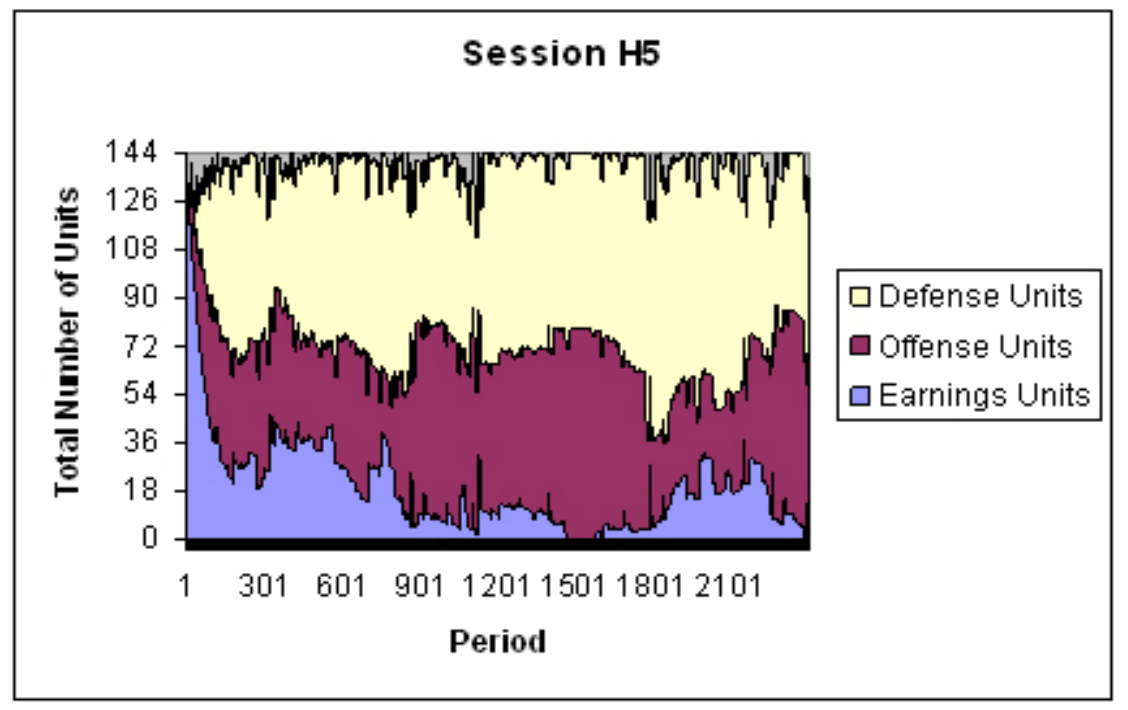

Session H6 
The subjects did not communicate in this session until after the halfway mark. Soon after they did, they began to discuss a cooperative agreement. The establishment of such an agreement never took place, however, and the session was particularly nasty, brutish and short. Three subjects were terminated. Two of these subjects were "resurrected" later in the session by transferred units from one of the remaining subjects, for which he received the praise, "bravo person 5.”

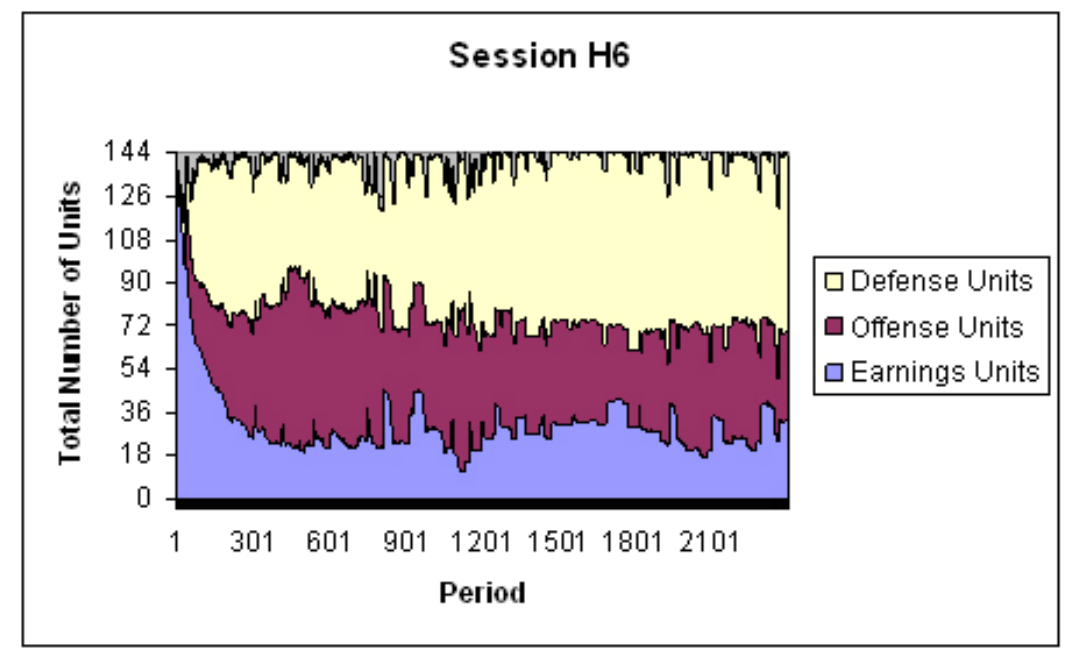

\section{Discussion}

In interpreting our results, we draw upon Miller (1992). The similarity between his work and our own is the common attempt to address issues of conflict within an environment where incentives may lead individuals to act against the interests of the collective unit. Miller posits three general features that may solve social discord: leadership, the creation of cooperative norms, and binding institutional provisions to maintain cooperation (p. 233).

These general insights are helpful in determining why some sessions led to such dismal levels of efficiency while others were able to achieve full cooperation. Each session that achieved full cooperation had particular subjects who constantly appealed to their fellow subjects to cease plundering. Most of the sessions that did not reach full cooperation had no such leadership in guiding the group to the cooperative outcome. In session $N 1$, for example, subject 3 emerged as a leader in focusing the group on a more cooperative outcome. Unfortunately, his comments came at the end of the session and the group did not act on them in time to increase overall efficiency. In session N2, subject 6 was the most vocal in coaxing both members of his own group and the other group to cease attacking and to put all of their units into earnings, and 
he was eventually successful in this endeavor. Subject 1 in session N6 impelled his fellow subjects to cease attacking, and hence the session was able to reach full cooperation more quickly than any other Nozick session. The result was that this was the most efficient session in the treatment.

Sessions N3, N4, and N5 were notable for their lack of leadership to achieve cooperation. There was no message that mentioned either the nature of the dilemma that the subjects faced or what actions would be necessary to attain full cooperation. This result is especially surprising when we take the Hobbes sessions into account. All six Hobbes sessions had at least one subject mention the dilemma and the cooperative strategy of putting all units into earnings. Only half of the Nozick sessions, however, explicitly expressed this mind-set. This leads us to the conjecture that the group formation mechanism in our experimental environment obfuscates the social problem to be solved by activating the evolutionarily deep “us-versus-them” mentality of tribes.

In another paper with free-form communication among its participants, Kimbrough, Smith, and Wilson (2008) investigate how impersonal distal exchange may grow out of local personal exchange in an economy with three geographically separated communities each connected to a local meeting area. To quantify how personal or impersonal their participants' exchanges are, they conduct a word count on the first-person plural pronoun "we" in the local and distal chat rooms. They argue that the word "we" reveals a personal connection between its user to another person or persons, and indeed find overwhelmingly that subjects use "we” more often in the local personal community.

In conducting a word count on our own transcripts, we find two results of interest. Because our participants all reside in the same visible area, "we" and "us" in the Nozick treatment could be inclusive of the small subgroup or the whole group of 6 participants in a way that the context of the discussion could not discriminate. However, the third personal plural pronouns "they" and "them" connote "others" or rival outsiders. These outsiders can be easily demarcated by color and private conversation in the Nozick treatment but not so in the Hobbes treatment. To test the conjecture that the Nozick treatment actuates an "us-versus-them" mindset in a way that the Hobbes treatment does not, we count the number of times "they" and "them" appear in the transcripts as well as how many times "we" and "us" appear. We conjecture that "they" and "them" will appear more often in the transcripts of the Nozick treatment than in the 
Hobbes treatment, but that there would be no difference in the use of "we" and "us." Table 2 reports the raw counts of these words.

\begin{tabular}{|c|c|c|}
\hline \multicolumn{3}{|c|}{ Table 2. Word Counts by Session } \\
\hline Session & We/Us & They/Them \\
\hline N1 & 2 & 1 \\
\hline$N 2$ & 40 & 16 \\
\hline$N 3$ & 7 & 1 \\
\hline$N 4$ & 17 & 21 \\
\hline N5 & 18 & 5 \\
\hline N6 & 74 & 17 \\
\hline Average & 26.3 & 10.2 \\
\hline \multicolumn{3}{|c|}{} \\
\hline H1 & 13 & 4 \\
\hline H2 & 39 & 4 \\
\hline H3 & 1 & 0 \\
\hline H4 & 26 & 2 \\
\hline H5 & 12 & 1 \\
\hline H6 & 3 & 0 \\
\hline Average & 15.7 & 1.8 \\
\hline
\end{tabular}

As conjectured, we find that the subjects use "they" and "them” statistically more often in the Nozick treatment than in the Hobbes treatment $\left(W_{6,6}=29, p\right.$-value $=0.0465$, one-sided test), and we cannot reject the null hypothesis of equal usage of "we" and "us" across treatments ( $W_{6,6}$ $=23, p$-value $=0.4848$, two-sided test).

The third feature, binding institutions, has less relevance within the parameters of our experiment, as subjects were unable to commit to any sort of binding agreement given the lack of external enforcement. However, in several sessions, subjects communicated "rules" that would govern subsequent behavior once full cooperation had been achieved. For example, in Session $H 2$ a subject was reluctant in putting all of their units into earnings so they retained some units in defense. This led another subject, who was the leader in focusing the subjects on the cooperative outcome, to proclaim "person 1, please take down your defense" followed by another subject to remark “you dont wanna be against everyone else.” The offending subject eventually acquiesced and put all of their units into earnings. In this case and in other sessions, it was apparent that the explicit threat of punishment created a provision militating against conflict. This was easier to accomplish once subjects placed the vast majority of units in earnings. To illustrate the 
significance of this point, neither session that achieved higher than $90 \%$ efficiency after the first 100 periods never subsequently fell below this mark.

\section{Conclusion}

Contrary to the Nozick hypothesis, we find that allowing subjects to form groups does not ameliorate conflict. If anything, it hinders the development of a collective regard for solving the dilemma by encouraging in- and out-group attitudes. The implication of these observations is that the ability to form private protective associations does not alone foster the necessary social cohesion to blunt plunder and eliminate costly expenditures on the defense against plunder. Sociality appears to be the key for a group to recognize the dilemma, and the emergence of a leader from within the group serves the vital role of encouraging participants to establish their own rules of order. As Hume (1740) appositely notes, "It is only a general sense of common interest; which sense all the members of the society express to one another, and which induces them to regulate their conduct by certain rules” (pp. 314-5).

It is deeply embedded in human nature for individuals to form tribal groups, yet such social formations may lead to both cooperation and conflict (Ridley 1997). To ameliorate the threat of conflict, it may be prudent to move individuals beyond factions by focusing attention on the consequences of conflict and the rewards of cooperation. Our experiments demonstrates that such endeavors appear to succeed where a general sense of common interest, leadership, and provisions against backslide are present.

\section{References}

Becker, G., Stigler, G., 1974. Law Enforcement, Malfeasance, and Compensation of Enforcers. Journal of Legal Studies 3, 1-18.

Buchanan, J., 1975. The Limits of Liberty. Liberty Fund, Indianapolis, IN.

Caplan, B., Stringham, E., 2002. Networks, Law, and the Paradox of Cooperation. Review of Austrian Economics 16, 309-326.

Cherry, T., Frykblom, P., Shogren, J., 2002. Hardnose the dictator. American Economic Review 92, 1218-1221.

Cowen, T., 1992. Law as a public good: the economics of anarchy. Economics and Philosophy 8, 249-267. 
Duffy, J., Kim, M., 2005. Anarchy in the laboratory (and the role of the state). Journal of Economic Behavior and Organization 56, 297-329.

Esteban, J., Sakovics, J., 2003. Olson vs. Coase: Coalitional Worth in Conflict. Theory and Decision 55, 339-357.

Friedman, D., 1989. The Machinery of Freedom. Open Court Publishing Company, La Salle, IL.

Friedman, D., 1994. Law as a private good: a response to Tyler Cowen on the economics of Anarchy. Economics and Philosophy 10, 319-327.

Hirshleifer, J., 2001. The Dark Side of the Force. Cambridge University Press, New York, NY.

Hume, D., 1740/2000. A Treatise of Human Nature. D. Norton and M. Norton, Eds. Oxford University Press, New York, NY.

Kimbrough, E., Smith, V.L., and Wilson, B.J., 2008. Historical property rights, sociality, and the emergence of impersonal exchange in long-distance trade. American Economic Review, 98(3), 1009-1039.

Landes, W., Posner, R., 1979. Adjudication as a Private Good. Journal of Legal Studies 8, 235284.

Miller, G., 1992. Managerial Dilemmas. Cambridge University Press, New York, NY.

Mokyr, J. 1990. The Lever of Riches. Oxford University Press, New York, NY.

Noh, S.J., 2002. Resource distribution and stable alliances with endogenous sharing rules. European Journal of Political Economy 18, 129-151.

Nozick, R., 1974. Anarchy, State and Utopia. Basic Books, New York, NY.

Ostrom, E., Walker, J., 1991. Communication in a Commons: Cooperation without External Enforcement. Laboratory Research in Political Economy, University of Michigan Press.

Powell, B., Wilson B.J., 2008. An experimental investigation of Hobbesian jungles. Journal of Behavioral and Economic Organization 66(3-4), 669-686.

Ridley, M., 1997. The Origins of Virtue. Viking Penguin, New York, NY.

Skaperdas, S., 1992. Cooperation, Conflict, and Power in the Absence of Property Rights. American Economic Review 80, 720-739.

Skaperdas, S., 1998. On the formation of alliances in conflict and contests. Public Choice 96, 2542. 
Smith, V.L., 1982. Microeconomic systems as an experimental science. American Economic Review 72, 923-955.

Smith, V.L., 2002. Method in experiment: Rhetoric and reality. Experimental Economics 5, 91110.

Smith, V.L. 2008. Rationality in Economics: Constructivist and Ecological Forms. Cambridge University Press, New York, NY.

Sutter, D., 1995. Asymmetric power relations and cooperation in anarchy. Southern Economic Journal 61, 602-613.

\section{Appendix: Experiment Instructions}

\section{Welcome}

This is an experiment in the economics of decision-making. Your earnings, which will be paid to you in CASH at the end of the experiment, will be determined partly by your decisions and partly by the decisions of others. If you have questions at any time while reading the instructions, please raise your hand and a lab monitor will assist you.

Each person is endowed with units of a fictitious good. The number of units of this fictitious good you will start this experiment with will be determined by your answers to a set of 10 questions. You will then be ranked depending on how many questions you answered correctly. Ties will be decided by giving a higher ranking to the person who finishes the quiz in the shortest amount of time. The higher your ranking, the more units you will start with.

Your initial endowment will be placed in your earnings. The number of units designated for earning is displayed in green under "Earn." in your box (the one labeled "YOU”). You will earn \$0.00077 per second for EACH unit you designate for this purpose. This is equivalent to \$0.0462 per minute per unit.

Earnings units can also be used to take Earnings units from other people, which we will call Offensive units (“Off.”). Alternatively, Earnings units can serve as units for defense (“Def.”). To move units to either Offense or Defense, click $\ll$ or $\gg$ buttons in your box (you will not be able to do this until the experiment starts). It will take 10 seconds for the units to transfer. You may also transfer units back to Earnings in the same manner.

Notice that the other players in the game have a (take) button next to their box. If you have designated some number of units for offense, then you can attempt to take a unit from another player. If you take a unit from someone else, it will be added to your Earnings units and taken away from their Earnings units. Once you attempt to take a unit, you will not be able to attempt again for a period of 20 seconds. Also, when you attempt to take a unit, a line will appear between your house and your targets. The line will slowly fade as time passes. Note that 
there are several other colored lines that will indicate certain functions throughout the experiment. A key for these can be found in the top right- and left-hand corners of the screen.

An attempt to take units from another person will be successful depending on how many units the taker has designated for Offense relative to how many units the target has designated for Defense.

Specifically, the probability that the taker is successful is:

Success rate of taker $=($ Units of Offense $) \div($ Units of Offense + Units of Defense $)$

For example, if you have 1 unit of Offense and the target has 1 unit of Defense, the probability that the attempt will be successful is $1 \div(1+1)$ or $50 \%$.

If the target has 2 units of Defense, then the probability that the attempt will be successful is $1 \div$ $(1+2)$ or $33 \%$.

If the target has no units of Defense, then the attempt will be successful $100 \%$ of the time.

You may communicate with others in the chat frame once the experiment starts. To send messages, type in the small box next to the send button and press the enter key or the send button. Your text will appear in the textbox above. You are free to discuss all aspects of the experiment, with the following exceptions: you may not reveal your name, discuss side payments, make threats, or engage in inappropriate language (including such shorthand as 'WTF'). If you do, you will be excused and you will forfeit your earnings.

[Begin Nozick treatment only instructions] Individuals can pool together units in a group. To start a group, use the Start Group button at the bottom right corner of your screen. The background color of your box will change to denote your group. To invite people to join your group, use the (invite) button next to their box.

Everyone in your group will pool their defense. This means that if there are 3 people in your group and each person has 5 units put towards defense, each person in your group will have a defense of 15.

Everyone in your group will also have the option to pool offense. To pool your offense with

another person click the (transfer control) button above their box. This will transfer control of the units you have designated for offense to that person. That means that if you have 5 units for offense and the person you have transferred control to has 6 units then the combined offense will be 11 and that person may then attempt to take from another person. If they are successful the person you have transferred control will receive one unit for each person (including themselves) that has transferred control to them. You may retract your offensive units at anytime by clicking transfer control button again.

You may chat with anyone in your group using the "Group chat" frame at the bottom of your screen. Only people currently in your group will be able to view and send messages in it. [End Nozick treatment only instructions] 
A summary of your earnings along with your current rate of earnings per second and the time elapsed in the experiment can be found in the "Summary" frame at the bottom right corner of your screen.

The sum of your earnings will be paid to you privately at the end of the experiment. You will not be told how long the experiment will last.

This is the end of the instructions. If you have any questions please raise your hand and a monitor will come by to answer them. If you are finished with the instructions please press Start. The instructions will remain on your screen until the experiment starts.

A summary of the information is displayed at the bottom of your screen. You will not be told how long the experiment will last. This is the end of the instructions. If you have any questions, please raise your hand and a monitor will come by to answer them. The experiment will begin when everyone has finished reading the instructions. 


\section{Economic Science Institute Working Papers}

2009

09-02 Jaworski, T. and Wilson, B. Go West Young Man: Self-selection and Endogenous Property Rights.

09-01 Gjerstad, S. Housing Market Price Tier Movements in an Expansion and Collapse.

2008

08-10 Dickhaut, J., Houser, D., Aimone, J., Tila, D. and Johnson, C. High Stakes Behavior with Low Payoffs: Inducing Preferences with Holt-Laury Gambles.

08-09 Stecher, J., Shields, T. and Dickhaut, J. Generating Ambiguity in the Laboratory.

08-08 Stecher, J., Lunawat, R., Pronin, K. and Dickhaut, J. Decision Making and Trade without Probabilities.

08-07 Dickhaut, J., Lungu, O., Smith, V., Xin, B. and Rustichini, A. A Neuronal Mechanism of Choice.

08-06 Anctil, R., Dickhaut, J., Johnson, K., and Kanodia, C. Does Information Transparency

Decrease Coordination Failure?

08-05 Tila, D. and Porter, D. Group Prediction in Information Markets With and Without Trading Information and Price Manipulation Incentives.

08-04 Caginalp, G., Hao, L., Porter, D. and Smith, V. Asset Market Reactions to News: An Experimental Study.

08-03 Thomas, C. and Wilson, B. Horizontal Product Differentiation in Auctions and Multilateral Negotiations.

08-02 Oprea, R., Wilson, B. and Zillante, A. War of Attrition: Evidence from a Laboratory Experiment on Market Exit.

08-01 Oprea, R., Porter, D., Hibbert, C., Hanson, R. and Tila, D. Can Manipulators Mislead Prediction Market Observers? 